\title{
Landing on one's foot: small-scale topographic features of habitat and the dispersion of juvenile intertidal gastropods
}

\author{
A. J. Underwood* \\ Centre for Research on Ecological Impacts of Coastal Cities, Marine Ecology Laboratories, A11, University of Sydney, \\ New South Wales 2006, Australia
}

\begin{abstract}
The associations of densities of very early recruits of mobile intertidal species with features of their habitat have rarely been examined in the field. Here, experimental manipulation of local topography (by provision of cracks, grooves and pits of various sizes) demonstrated species-specific responses by animals naturally recruiting into experimental plots. Densities of small $(<3 \mathrm{~mm})$ juvenile snails (Austrocochlea porcata, Bembicium nanum and Nerita atramentosa) and limpets (Cellana tramoserica and Patelloida latistrigata) varied among experimental topographies in consistent ways. Although local densities were influenced by appropriate topographic features, only N. atramentosa and $P$. latistrigata showed increased density per area of shore with alteration of topography. For the former species, provision of grooves and large pits also caused enhanced densities on open surfaces. $P$. latistrigata had decreased densities on open surfaces, but very much enhanced densities in grooves and other features, thus increasing total numbers in an area. Experimental transplantation and subsequent movements of small juveniles demonstrated very similar patterns to those shown after natural recruitment, indicating behavioural responses to local topography. Responses to small-scale topography can explain small-scale variation in numbers of very early recruits of intertidal gastropods.
\end{abstract}

KEY WORDS: Dispersion · Juvenile gastropods $\cdot$ Microhabitat $\cdot$ Rocky shore $\cdot$ Topography

\section{INTRODUCTION}

It is a widespread and frequent observation that mobile species are distributed differentially and, often in patchy arrangements across any piece of habitat. Where consistent and repeatable differences in the spatial arrangements of different species occur, there are several ecological puzzles to solve. Notable is the need to be able to explain which features of habitat - physical barriers to movement, physical or biological resources, etc. - are associated with the different responses by the animals. There also should be explanations of the processes that create or maintain (once created) the patterns. A complete analysis would therefore involve identification of patterns and understanding of their causes and, where possible, the consequences to the organisms or to other species that they influence.
On rocky intertidal shores in many parts of the world, there are strikingly different patterns in the ways different species are dispersed (overviews in Dakin 1953, Lewis 1964, Ricketts et al. 1968, Morton \& Miller 1973). Considerable effort has been expended in ecological analyses of such distributions (reviews by Connell 1972, Paine 1977, Underwood 2000).

At small spatial scales, there has been a lot of work on the establishment of intertidal distributions of animals and plants by examination of processes of arrival, settlement, and subsequent behaviour of organisms (Wethey 1984, Butman 1987, Eckman 1996). Most of this work has, however, been on animals that are sessile after settlement, notably barnacles, tubeworms, bryozoans and the like. This has long ago led to a rich understanding of the repertoire of small-scale behav- 
ioural reactions to stimuli from the habitat and how these influence the tendency to settle in particular places (see, particularly, the vast body of work by the earlier researchers, such as Barnes \& Powell 1950 and Crisp 1974).

Much of this work was done under laboratory conditions, but extensions into natural habitats have identified complex responses under conditions in the field to various stimuli and features of habitat (Denley \& Underwood 1979, Strathmann et al. 1981). These have been coupled with good quantitative assessments of how early stages of intertidal life can be patchy in space (de Wolff 1973, Caffey 1985) and/or time (Wethey 1984).

There has, however, been considerably less work on relations between distribution of young individuals and features of habitat for species that are more mobile after settlement. This is particularly true of gastropods, which are often numerous and important components of intertidal assemblages (Stimson 1970, Branch 1981, Underwood 1985). There have been interesting and informative studies of the cues used to trigger settlement of abalone (Morse et al. 1984) and responses to cues for settlement from food by some opisthobranchs (Thompson 1958, Hadfield 1978). There has also been a (so-far unique) description of rapid expansion of shells of newly-settled Littorina neritoides. Individuals that happen to land in crevices when they arrive on the shore in a wave are able to survive by this sudden change of size that wedges them into the crevice (Fretter \& Manly 1977). There have also been accounts of passive entrapment of newly-arrived juveniles of Rissoa parva in the complex fronds of foliose algae (Wigham 1975). There are several experimental accounts of 'bulldozing' or accidental grazing by adult limpets on small juveniles, leading to negative correlations in their densities (Dayton 1971, Underwood et al. 1983, Branch 1984). There are few other studies on the causes of spatial pattern in the distribution of juvenile gastropods (Underwood 1979, McQuaid 1996).

Intertidal habitats in New South Wales (Australia) are home for a variety of grazing gastropods (Dakin 1953). Adults are not distributed in the same ways across features of the habitat such as pools and algae (Underwood 1976a,b, Chapman 1994).

From sheltered to exposed shores, there are differences in the mix of species present (Underwood 1981). There have been successful experimental analyses of some of these, such as the relationships between the limpet Patelloida latistrigata and barnacles (Creese 1982, Underwood et al. 1983). At small spatial scalesfrom $10 \mathrm{~s}$ of $\mathrm{cm}$ to $1 \mathrm{~m}$-there is also considerable variation in numbers of juveniles of the common species (A. J. Underwood unpubl.). Some of this is apparently related to features of habitat.
Following the detailed analyses of influences of topography on the small-scale variability in numbers of high-shore littorinid snails (Underwood \& Chapman 1989, Chapman 1994, Chapman \& Underwood 1994), this study describes an experimental analysis of influences of topography on the distributions of juvenile snails and limpets. Several topographic features of shores, including narrow cracks and small pits, wider grooves and large pits were established experimentally at mid-shore levels in randomly-chosen sites on sheltered or exposed shores. When juvenile snails and limpets were found in those experimental arrays, their numbers were analysed to test hypotheses about responses to different topographic features. When juveniles were in sufficient numbers, they were transplanted into the experimental areas to test the hypothesis that ultimate patterns were not solely determined by initial arrangements during settlement.

One major problem in investigations of early lifehistory stages of intertidal gastropods is that there are rarely large numbers present in any area at any time. Numbers in small experimental plots are therefore small and extremely unpredictable. This, in part, explains why there have been many more studies of barnacles, which at least have the decency to settle in large numbers at some times in some places. The analysis of such data, in which animals are sparse on any single occasion in any single place, also causes problems, so meta-analytical methods to compare the results of numerous small experiments become necessary. As a consequence, numerous experiments were done over several years in order to collect an analysable set of data.

\section{MATERIALS AND METHODS}

Study sites and juvenile gastropods. Experimental plots ( 5 treatments and 2 controls) were established in each of 2 sheltered areas (Hormosira flats and the Boulders) and 2 wave-exposed areas (the Point and near the Wreck) at the Cape Banks Scientific Marine Research Area, Botany Bay (New South Wales). The sheltered areas had about $30 \%$ cover of encrusting Hildenbrandia rubra and populations of several gastropods and the grazing starfish Patiriella exigua. The exposed areas originally had a cover of about $40 \%$ of the barnacle Tesseropora rosea, but this changed naturally during the experiments (from about $10 \%$ to $70 \%$ over the whole period; see Underwood et al. 1983). For these experiments, snails and limpets of a maximal dimension of $3 \mathrm{~mm}$ (length for limpets and Nerita atramentosa; width for the other 2 snails) were defined to be juveniles. The dispersion of adults and larger juveniles of these species were described in detail by Underwood (1976a,b). 
Manipulation of surfaces. Two series of experiments were done. In the first, features of habitat were created by altering the topography of rocky surfaces. At randomly-chosen intervals between 1985 and 1989, experimental treatments were searched and all juvenile gastropods were counted (i.e. all snails and limpets $\leq 3 \mathrm{~mm}$ maximal shell dimension). Treatments were created in $25 \times 25 \mathrm{~cm}$ plots as follows:

Small Pits: $20 \mathrm{~mm}$ deep; $6 \mathrm{~mm}$ diameter; 10 pits in a plot (area $=2.8 \mathrm{~cm}^{2} ; 0.4 \%$ of a plot).

Medium Pits: $20 \mathrm{~mm}$ deep; $30 \mathrm{~mm}$ diameter; 10 pits in a plot (area $=70.7 \mathrm{~cm}^{2} ; 11 \%$ of a plot).

Large Pits: $20 \mathrm{~mm}$ deep; $75 \mathrm{~mm}$ diameter; 4 pits in a plot (area $=176.7 \mathrm{~cm}^{2} ; 28 \%$ of a plot).

Cracks: $20 \mathrm{~mm}$ deep; $5 \mathrm{~mm}$ wide; $120 \mathrm{~mm}$ long; 5 cracks in a plot (area $=30 \mathrm{~cm}^{2} ; 4.8 \%$ of a plot).

Grooves: $20 \mathrm{~mm}$ deep; $20 \mathrm{~mm}$ wide (square crosssection); $120 \mathrm{~mm}$ long; 5 grooves in a plot (area = $120 \mathrm{~cm}^{2} ; 19 \%$ of a plot).

Each plot was marked in 2 diagonally opposite corners by drilling small holes. For each treatment, 3 plots were established in a site, with 2 controls. The first (unmanipulated control) was simply marked in 2 corners. The second (cleared control) was marked, but all existing animals were removed because this was also done in the manipulated plots. This was done after every census of snails - all plots were cleared again. In some areas, a third control was used; this consisted of using a wire brush to remove the surface of the rock to control for the appearance of a new surface, which was inevitable when originally making the treatments. This could only be done to simulate large pits and grooves (all other treatments were too small). All analyses showed no differences compared with the other controls, so these plots were not examined further.

Barnacles were present at some times in some plots, haphazardly creating considerable topographic complexity in some treatments at some times. To prevent influences of such unplanned topographic structures, all barnacles were cleared from all experimental plots and a surrounding 'buffer' of about $5 \mathrm{~cm}$ (i.e. $35 \times$ $35 \mathrm{~cm}$ total area).

At each time of sampling (August, September, November 1985; May, July, September, December, 1986; February, April, June, August, 1987; March, August, 1988; March, September, 1989), all juvenile gastropods were counted in each plot (in each artificial structure and in the untreated part of the plot). This provided 3 different measures to test different hypotheses:

(1) Total number of a species per plot; these data were used to test the hypothesis that topographic features will enhance the numbers of animals in an area;

(2) Number of animals of a species per unit area of each type of experimental surface; these data test hypotheses that there will be differences among the particular treatments;

(3) Number of a species per unit area of unmanipulated surface in plots with experimental topographies; these data allow tests of the hypothesis that topographic features only alter local dispersion and make no difference to overall density of animals. For example, numbers per unit area of some experimental topography may be greater than per unit area of natural surface, but numbers per unit area of the surrounding surface of the plot may be correspondingly smaller. As result, there will be no increase in numbers in the whole plot-the experimental surfaces cause a redistribution of the same number of animals.

Areas of the surface of experimental treatments were calculated assuming that the total internal surface of a treatment matters to a small snail. As an example, the area of a groove is a base and 2 sides of $20 \times 120 \mathrm{~mm}$ each, or $3 \times 2400 \mathrm{~mm}^{2}=7200 \mathrm{~mm}^{2}$, and 2 ends of $20 \times$ $20 \mathrm{~mm}$ each, or $2 \times 400 \mathrm{~mm}^{2}=800 \mathrm{~mm}^{2}-$ a total of $8000 \mathrm{~mm}^{2}$. Densities were calculated for each treatment.

Manipulations of animals. On 4 occasions in 1988 (March, August) and 1989 (March, September), snails were experimentally manipulated to test hypotheses about their behaviour in response to topographic features. Ten replicate snails (Nerita atramentosa, Austrocochlea porcata at all times; Bembicium nanum in August, 1988 and September, 1989) or limpet (Patelloida latistrigata at all times) were introduced to 2 replicate experimental plots of treatments at all 4 sites.

Snails of some species were put into the same plots, but to avoid any non-independence in behaviour of snails of different species as much as possible, only 1 species was put into a plot of the 3 plots available for each treatment. In fact, the likelihood of these tiny snails influencing each other is very small. Although not formally analysed, data did not indicate non-independence or interactions between species. Densities of transplanted animals were small, so that they could only rarely encounter each other or each other's trails.

Due to losses of snails from exposed areas, only Nerita atramentosa and Patelloida latistrigata were put into exposed areas after the first 2 times. Similarly, because $P$. latistrigata were all lost from sheltered areas, they were put only into exposed areas after the second time. It proved impossible to move tiny Cellana tramoserica without breaking their shells, so experimental transplantation of these limpets was abandoned after the first attempt.

Experimental animals were carefully picked up and put onto the surfaces of the plots. Moving them to the unmanipulated control plots (UC in the previous section) is equivalent to the translocation control required for such experiments (Chapman 1986). A further control consisted of animals that were picked up and 
replaced on the surface in the position they were found (a disturbance control); all other snails were removed from the 3 plots for these controls. Animals were too small and numerous to mark individually, so they were given 1 or 2 dots of quick-drying paint in different colours to mark each treatment. A further set of 3 plots in which animals were painted in situ with no further disturbance was used to control for effects of disturbance, i.e. an 'absolute' control except for painting. In analyses, comparisons were first made of this last control, the disturbance control and the unmanipulated plots with unmanipulated surfaces (UC) to detect any artefacts due to disturbance or translocation. Then, the experimental topographies were compared with the UC.

After 1 and 2 days, the numbers of marked animals in every treatment were recorded as the total recovered from the 20 individuals originally transplanted into the 2 replicate plots.

Analysis of results. Results were generally very variable-largely because of variation from time to time in recruitments of the various species. As a result, data were not available for all times of sampling, nor from all sites. Numbers of juveniles in experimental plots were generally very small. For the snail Austrocochlea porcata average numbers were 2 to 4 per plot in sites and at times where/when it was considered that there were enough snails for results to be meaningful. For Bembicium nanum and Nerita atramentosa, the means were 1 to 2 per plot. The limpets Cellana tramoserica and Patelloida latistrigata were present at mean densities of 3 to 5 , and 6 to 16 per plot, respectively. Juveniles of a few other species were present in experimental areas, but only 1 or 2 over all plots at any time or place, so no useful data were obtained.

As a consequence of the unpredictably large variations in recruitment, analyses were done by rank-order tests. Thus, at any given time or place sampled, densities per unit area (of the whole plot, of the surface minus treatments, or of each of the treatments) were summed from the 3 replicate plots and arranged in rank order across the various treatments. Such a ranking was then available for a set of times and places sampled. Assuming independence of data from time to time and place to place, the rank-orders were then examined by Anderson's tests (Anderson 1959; see also Underwood \& Chapman 1992, Underwood 1997). In essence, these test the null hypothesis that there is no pattern in ranks across several independent rankings. In contrast, if some experimental treatment consistently gains more juveniles of a species, it would consistently get higher rankings. As listed in 'Results', the number of rankings available ranged from 7 to 22 for the first series of experiments and 4 to 22 for the experimental transplants.

Where significant differences were detected according to Anderson's test, multiple comparisons were made using pair-wise Friedman tests (Anderson 1959; Winer et al. 1991). These are considered reliable for any situation where the product of $n$ (number of rankings) and $r$ (number of treatments compared) is $>23$ (Winer et al. 1991). In the analyses here, $r=6$ for comparing experimental topographies and $r=3$ for comparing controls in experimental transplants. $n \times r$ ranged from 42 (for Cellana tramoserica) to 132 (for Patelloida latistrigata), safely satisfying assumptions of the tests. The only exceptions were for comparisons of 3 controls in experimental transplants of Austrocochlea porcata $(n \times r=24)$, sampling of topographies for Bembicium nanum $(n \times r=24)$ and in comparing controls for transplants of $B$. nanum $(n \times r=6)$. In these 3 cases, there were no significant differences in Anderson's tests and therefore no Friedman statistical procedures were used. The only other exception was the comparison of 3 controls for experimental transplants of $P$. latistrigata $(n \times r=12)$, but here the differences found were large, so the tests were probably reliable despite the possible violation of assumptions. Pair-wise tests were not orthogonal (data for each treatment were used in comparison with several other treatments). Probabilities were adjusted by the Dunn-Sidak procedure (Dunn 1961; Day \& Quinn 1989) to maintain a notional $\alpha=0.05$ over each set of comparisons.

The assumption of independence (not across treatments - they cannot be independent because they are ranked across all possible treatments) is realistic from one site to another. They are far enough apart to have quite unrelated recruitment. From one time of sampling to another the assumption may not be correct, given that the same plots were re-sampled (see Caffey 1985, for an example involving barnacles). No formal comparisons were made across sites. In some related experiments on the snail Littorina unifasciata (Underwood \& Chapman 1992), there were sufficient places and times sampled to allow randomly drawn data from different sites and therefore completely independent analyses. The same patterns were found as for the complete set of data. It seems reasonable to assume that recruitments are sufficiently independent from time to time so that data from the same sites do not cause problems for interpretations.

\section{RESULTS}

\section{Austrocochlea porcata}

No juvenile Austrocochlea porcata were found in experimental plots on exposed shores. There were enough juveniles (an average of 3 per unmanipulated control plot; Table 1) on the 2 sheltered shores to analyse results on 4 sampling occasions (i.e. data were 
Table 1. Austrocochlea porcata. Data (mean; SE in parentheses) from 4 Times in 2 Sheltered places $(n=8)$. Mean ranks are largest (6) to smallest (1). Control and Disturbed Control only apply to experimental transplants. ${ }^{\mathrm{a}-\mathrm{d}}$ Groups of means which differ by Friedman tests. ${ }^{x}$ Means not different by Anderson's test for comparisons of controls analysed separately from experimental transplants

\begin{tabular}{|lcccccc|}
\hline & \multicolumn{3}{c}{$\begin{array}{c}\text { Sampling } \\
\text { Density }\end{array}$} & \multicolumn{3}{c|}{ Transplants } \\
& (ind. m $\left.^{-2}\right)$ & & \multicolumn{2}{c}{ No. } & Rank \\
& & & & & \\
\hline Unmanipulated & 48.0 & $(6.2)$ & $5.5^{\mathrm{a}}$ & $10.5^{\mathrm{x}}(1.1)$ & $5.6^{\mathrm{a}}$ \\
$\quad$ Surface & & & & & & \\
Small Pits & $20.6(11.1)$ & $1.1^{\mathrm{d}}$ & $1.6(0.4)$ & $1.2^{\mathrm{d}}$ \\
Medium Pits & 32.2 & $(3.4)$ & $3.2^{\mathrm{c}}$ & $5.4(0.6)$ & $3.3^{\mathrm{c}}$ \\
Large Pits & 34.2 & $(4.1)$ & $3.5^{\mathrm{c}}$ & $4.5(0.7)$ & $2.7^{\mathrm{c}}$ \\
Cracks & 43.2 & $(4.5)$ & $4.6^{\mathrm{b}}$ & $8.5(0.7)$ & $4.8^{\mathrm{b}}$ \\
Grooves & 30.2 & $(3.1)$ & $3.1^{\mathrm{c}}$ & $5.5(0.4)$ & $3.4^{\mathrm{c}}$ \\
Control & & & & $11.3^{\mathrm{x}}(1.6)$ & - \\
Disturbed Control & & & & $8.8^{\mathrm{x}}(1.3)$ & - \\
\hline
\end{tabular}

available for 8 series of experiments). On these sheltered shores, there were no significant differences among experimental plots for the total numbers of juveniles per unit area of plot (Hypothesis (1) in 'Materials and methods'). Nor were there any differences in densities on the surfaces (i.e. the area of the plot minus the areas taken up by experimental topographies) of different experimental plots (hypotheses identified as (3)). Therefore, adding different experimental topographies did not alter the numbers of snails on open surfaces in the plots. There were, however, consistently more snails on open surfaces than in any of the treatments. There were also more snails in cracks than in large pits, medium pits or grooves, which all had more snails than did small pits (Table 1).

Numbers of experimentally transplanted animals found again averaged 6.1 per experimental plot (out of 20 transplanted to the 2 replicate plots) over 4 times and 2 types of shore. There were no differences in mean numbers on experimental surfaces compared with untouched and disturbed controls, so there were no obvious artefacts due to disturbance or translocation. The patterns of difference among experimental topographies shown by numbers and ranks of treatments matched exactly those from the sampling experiments (Table 1). Juvenile Austrocochlea porcata therefore remained in experimental topographies when put there in relative numbers similar to their natural arrivals to such situations.

\section{Bembicium nanum}

Juvenile Bembicium nanum were only found at a total of 4 times in the 2 sheltered locations, at an average density of 1.5 per unmanipulated control plot
Table 2. Bembicium nanum. Data (mean; SE in parentheses) from 4 Times in 2 Sheltered places $(n=8)$ for sampling experiments, and 2 Times in 2 Sheltered places $(n=4)$ for transplants. Mean ranks are largest (6) to smallest (1). Control and Disturbed Control only apply to experimental transplants.

${ }^{\mathrm{a}-\mathrm{d}}$ Groups of means which differ by Friedman tests. ${ }^{\mathrm{X}, \mathrm{Y}}$ Means not different by Anderson's test for comparisons of controls, analysed separately from experimental transplants (x) and for experimental transplants (y)

\begin{tabular}{|c|c|c|c|c|}
\hline & \multicolumn{2}{|c|}{ Sampling } & \multicolumn{2}{|c|}{ Transplants } \\
\hline & $\begin{array}{l}\text { Density } \\
\left(\text { ind. } \mathrm{m}^{-2} \text { ) }\right.\end{array}$ & Rank & $\begin{array}{l}\text { No. } \\
\text { recovered }\end{array}$ & Rank \\
\hline $\begin{array}{l}\text { Unmanipulated } \\
\text { Surface }\end{array}$ & $27.4 \quad(3.4)$ & $4.9^{\mathrm{a}}$ & $13.0^{\mathrm{x}}(2.5)$ & $3.3^{\mathrm{y}}$ \\
\hline Small Pits & $11.8(12.7)$ & $1.7^{\mathrm{c}}$ & $13.0(1.4)$ & $3.7^{\mathrm{Y}}$ \\
\hline Medium Pits & $18.4 \quad(4.0)$ & $3.6^{\mathrm{b}}$ & $12.5(1.7)$ & $3.0^{y}$ \\
\hline Large Pits & $24.8 \quad(3.6)$ & $4.3^{\mathrm{a}}$ & $12.5(1.6)$ & $3.0^{\mathrm{y}}$ \\
\hline Cracks & $6.8 \quad(2.5)$ & $1.7^{\mathrm{c}}$ & $14.3(2.0)$ & $4.4^{\mathrm{y}}$ \\
\hline Grooves & $26.2(2.0)$ & $4.8^{\mathrm{a}}$ & $12.8(1.4)$ & $3.6^{\mathrm{y}}$ \\
\hline Control & & & $15.0^{\mathrm{x}}(1.6)$ & - \\
\hline Disturbed Control & & & $13.5^{\mathrm{x}}(1.7)$ & - \\
\hline
\end{tabular}

(Table 2). As with Austrocochlea constricta, mean numbers per unit area over the whole experimental plots did not differ among treatments. Nor were there differences in densities on the surfaces (i.e. the area of the plot minus the areas taken up by experimental topographies) of different experimental plots. There were, however, more animals on surfaces of plots and in large pits and grooves (which did not differ from one another) than in medium pits, which had more snails than did small pits or cracks.

Very few experimentally transplanted snails were recovered and, consequently, there were no differences in mean numbers among the experimental treatments.

\section{Cellana tramoserica}

Sufficient juvenile Cellana tramoserica were found for analyses of 7 occasions, at an average of 3.6 limpets per unmanipulated control plot (Table 3).

Table 3. Cellana tramoserica. Data (mean; SE in parentheses) from 4 Times in 1 Sheltered places and 3 Times in the second Sheltered place $(n=7)$; there were no experimental transplants. Mean ranks are largest (6) to smallest (1). ${ }^{\mathrm{a}-\mathrm{d}}$ Groups of means which differ by Friedman tests

\begin{tabular}{|lcc|}
\hline & \multicolumn{2}{c|}{ Sampling } \\
& $\begin{array}{c}\text { Density } \\
\left.\text { (ind. } \mathrm{m}^{-2}\right)\end{array}$ & Rank \\
\hline Unmanipulated Surface & $58.7(13.5)$ & $5.3^{\mathrm{a}}$ \\
Small Pits & $0 \quad(0)$ & $0.4^{\mathrm{d}}$ \\
Medium Pits & $19.3(3.2)$ & $3.0^{\mathrm{c}}$ \\
Large Pits & $43.0(5.2)$ & $4.5^{\mathrm{b}}$ \\
Cracks & $11.9(0)$ & $2.6^{\mathrm{c}}$ \\
Grooves & $47.6(3.7)$ & $5.2^{\mathrm{a}}$ \\
\hline
\end{tabular}


Mean numbers of juvenile limpets showed the same pattern as above for Bembicium nanum (Table 3), except that there were significantly more $C$. tramoserica on surfaces of unmanipulated control plots or in grooves than in large pits. Numbers of juvenile limpets in whole plots were not different and numbers on surfaces adjusted to remove the area of experimental topographies were also similar across all experimental plots.

\section{Nerita atramentosa}

On 12 occasions, sufficient Nerita atramentosa were found, at an average density of 1 to 2 per plot across all plots. Results for $N$. atramentosa were more complex than for the species described above. There were, on average, more juveniles of this species in grooves or large pits, than in medium pits, which had more than did cracks, small pits or unmanipulated control surfaces (Table 4).

In contrast to all other species, there were also, on average, more juveniles in whole experimental plots where there were grooves or large pits than in plots with medium pits. All of these had more juveniles than found in whole plots with cracks, small pits or no experimental topographies (i.e. unmanipulated controls).

Again, uniquely among the species examined, there were differences in densities of snails on open surfaces, calculated as the area of a plot minus the areas occupied by experimental topographies (Table 4). Densities on these adjusted surfaces followed the same pattern as for whole plots and for experimental topographies, except that there were more snails on surfaces where there were large pits than where there were grooves. Thus, in general, some experimental topographies had more snails in them than were on bare surfaces. In plots with these experimental topographies, there were also more snails on the surrounding bare surfaces and, consequently, overall increases in densities across the whole plot.

Experimentally transplanted snails showed the same pattern as those found in sampling, except that grooves and large pits always had similar densities.

Note, however, that substantially fewer snails were recovered after transplantion to unmanipulated surfaces than in controls and disturbance controls (Table 4), indicating an artefact due to translocation. The differences shown among the experimental topographies are therefore only demonstrated for animals that had been placed in unfamiliar surroundings. The patterns were nevertheless similar for undisturbed animals in the sampling of experimental topographies described previously.

\section{Patelloida latistrigata}

Juvenile Patelloida latistrigata were only found in the 2 exposed locations, but sufficiently often to obtain 22 sets of experimental data, at an average number of 7.7 per unmanipulated control plot. There were very clear patterns of difference. There were more limpets in grooves than in cracks, which did not differ from large pits, medium pits or surfaces. Small pits had fewer limpets than in any other treatment (Table 5). There were also more juvenile $P$. latistrigata in whole plots containing grooves than in plots with any other treatment.

Examination of controls and disturbed control showed reduced recovery of transplanted animals in the latter (mean of 13.3 compared with 3.8; Table 5). Despite the artefact associated with disturbance, there was no further reduction in recovery of limpets

Table 4. Nerita atramentosa. Data (mean; SE in parentheses) from 6 Times in 2 Sheltered places $(n=12)$ for sampling experiments and 4 Times on 2 sheltered and 2 exposed shores $(n=16)$ for transplants. 'Adjusted surface' refers to the area of a plot minus the surface (plan) area of experimental topographies. Mean ranks are largest (6) to smallest (1). ${ }^{\text {a-d }}$ Groups of means which differ by Friedman tests

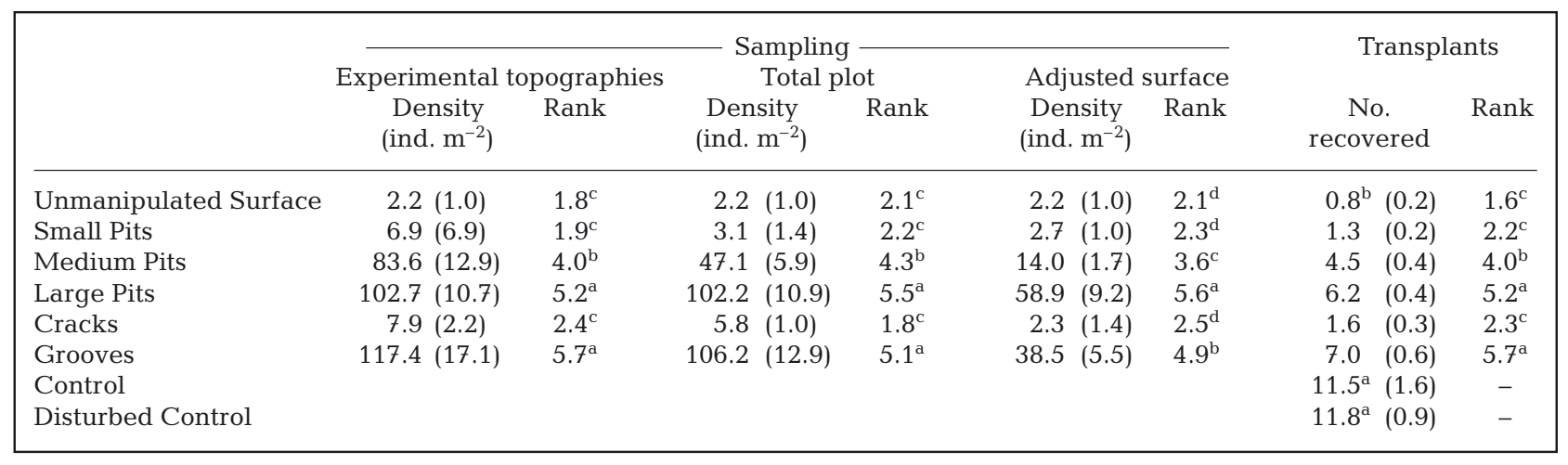


Table 5. Patelloida latistrigata. Data (mean; SE in parentheses) from 11 Times in 2 Sheltered places $(n=22)$ for sampling experiments and 4 Times on 2 exposed shores $(n=8)$ for transplants. Ranks are largest (6) to smallest (1). Control and Disturbed Control only apply to experimental transplants. ${ }^{\mathrm{a}-\mathrm{d}}$ Groups of means which differ by Friedman tests

\begin{tabular}{|c|c|c|c|c|}
\hline & \multicolumn{2}{|c|}{ Sampling } & \multicolumn{2}{|c|}{ Transplants } \\
\hline & $\begin{array}{l}\text { Density } \\
\text { (ind. } \mathrm{m}^{-2} \text { ) }\end{array}$ & Rank & $\begin{array}{l}\text { No. } \\
\text { recovered }\end{array}$ & Rank \\
\hline Surface & $123.6(18.7)$ & $3.6^{\mathrm{b}}$ & $3.1^{\mathrm{b}}(0.6)$ & $1.6^{\mathrm{d}}$ \\
\hline Small Pits & $26.2(8.4)$ & $1.9^{\mathrm{c}}$ & $4.6 \quad(1.1)$ & $2.8^{\mathrm{c}}$ \\
\hline Medium Pits & $177.1(42.1)$ & $3.3^{\mathrm{b}}$ & $10.6(0.6)$ & $4.5^{\mathrm{b}}$ \\
\hline Large Pits & $185.9(48.4)$ & $3.4^{\mathrm{b}}$ & $6.8 \quad(0.8)$ & $3.5^{\mathrm{c}}$ \\
\hline Cracks & $175.3(51.6)$ & $3.7^{\mathrm{b}}$ & $5.9 \quad(0.5)$ & $2.8^{\mathrm{c}}$ \\
\hline Grooves & $346.2(77.8)$ & $5.1^{\mathrm{a}}$ & $14.6(1.0)$ & $5.8^{\mathrm{a}}$ \\
\hline Control & & & $13.3^{\mathrm{a}}(0.5)$ & - \\
\hline Disturbed Control & & & $3.8^{\mathrm{b}}(0.5)$ & - \\
\hline
\end{tabular}

from the surface of experimental plots, so experimental treatments could be compared, but results may only apply to disturbed limpets. The limpets were then much more abundant in grooves than any other treatment. There were significantly more limpets in medium pits than in cracks or large pits, which had greater densities than on open surfaces or in small pits.

The other notable result for Patelloida latistrigata was that there were more juvenile limpets per unit area in whole plots which contained grooves or large pits. In these plots, there were fewer limpets on open surfaces than found on open surfaces in control plots. These results imply that grooves allow greater densities of limpets, some of which may have been animals that would otherwise have been on the open surface. In addition, there are extra limpets that would otherwise not have been present.

In contrast, large pits supported an enhanced density of limpets, some of which came from open surfaces. The numbers of juveniles in large pits were, however, insufficient to increase the overall densities in whole plots.

\section{DISCUSSION}

The results demonstrate different patterns from species to species in relation to different topographic features (summarized in Table 6). Results from sampling juveniles that had naturally taken up positions in plots were generally matched by the patterns found for transplanted animals. This strongly suggests that densities are the outcome of active choice - transplanted animals exercised choices by moving from open surfaces into topographic features. Except for the limpet Patelloida latistrigata, it is possible that the juveniles might have been rolled around by waves, resulting in the patterns observed. This is not likely for 3 reasons: (1) This process should have resulted in random allocations of animals to treatments, per unit area of treatments; this was not the case-juveniles were not randomly allocated to treatments. (2) The patterns across experimental topographies were fairly consistent for each species from one experiment to another, which is an unlikely outcome if random processes were operating. (3) There were species-specific patterns of occupation of the different topographies; given that juveniles of Austrocochlea porcata, Bembicium nanum and Nerita atramentosa were of very similar sizes, shapes and weights, it is quite unreasonable to propose that they were passively moved to different topographies in consistent, species-specifically different ways.

It is, however, not known whether these juveniles finished up in different topographic features having actively crawled to and stayed in them, or whether they were moved passively and then had different tendencies to remain in particular topographies. That Patelloida latistrigata also showed differences among treatments suggests active movement, because these animals are definitely not moved small distances by being shoved around by waves or swash. When hit by waves of sufficient force to move them, these limpets are washed away (pers. obs.). So, on balance, densities of juveniles of these species were affected by responses to local differences in topography_creating species-specific patterns of variation from place to place at small ( $\mathrm{cm}$ to $10 \mathrm{~s}$ of $\mathrm{cm}$ ) spatial scales.

Table 6. Summary of results on unmanipulated rocky surfaces and on plots with artificial experimental topographies

\begin{tabular}{|lll|}
\hline Austrocochlea porcata & Sampling & Surface $>$ Cracks $>$ Large Pits $=$ Med. Pits $=$ Grooves $>$ Small Pits \\
& Transplants & Surface $>$ Cracks $>$ Med. Pits $=$ Grooves $=$ Large Pits $>$ Small Pits \\
Bembicium nanum & Sampling & Surface $=$ Grooves $=$ Large Pits $>$ Med. Pits $>$ Small Pits $=$ Cracks \\
& Transplants & Cracks $=$ Surface $=$ Small Pits $=$ Grooves $=$ Med. Pits $=$ Large Pits \\
Cellana tramoserica & Sampling & Surface $=$ Grooves $=$ Large Pits $>$ Med. Pits $=$ Cracks $>$ Small Pits \\
Nerita atramentosa & Sampling & Grooves $=$ Large Pits $>$ Med. Pits $>$ Cracks $=$ Small Pits $=$ Surface \\
& Transplants & Grooves $=$ Large Pits $>$ Med. Pits $>$ Cracks $=$ Small Pits $=$ Surface \\
Patelloida latistrigata & Sampling & Grooves $>$ Cracks $=$ Large Pits $=$ Med. Pits $=$ Surface $>$ Small Pits \\
& Transplants & Grooves $>$ Med. Pits $>$ Cracks $=$ Large Pits $=$ Surface $>$ Small Pits
\end{tabular}


Even though densities of most species were greater in some of the experimental topographies, only Nerita atramentosa and Patelloida latistrigata showed patterns of increased density in whole plots with these features. In the case of $N$. atramentosa, medium and large pits and grooves all caused greater densities of snails on open surfaces and therefore in whole plots. In the case of $P$. latistrigata, plots with grooves or large pits had enhanced densities of limpets, but the open surfaces of plots had reduced densities. The latter situation is akin to the enhancement of densities of littorinid snails described by e.g. Raffaelli \& Hughes (1978) and other authors discussed below. The densities of these species are limited by availability of suitable crevices or other relevant topographic features. This finding for $P$. latistrigata is consistent with its dependence on topographic complexity for survival in areas where there is competition from other grazers or where wave action is strong (Creese 1982, Underwood et al. 1983).

The pattern shown by Nerita atramentosa is different from those described for other species in that numbers are locally enhanced in plots with suitable topographic features. The presence of these features enables increased numbers of snails to inhabit open surfaces than is the case where these features are absent. Presumably, the presence of suitable grooves and pits makes it possible for $N$. atramentosa to retreat into shelter during periods of inclement weather, but in other weather conditions the snails can persist out on open surfaces (as is the case for the predatory whelk Morula marginalba, which needs crevices and shelters into which it retreats when weather is unfavourable; Moran 1985, Fairweather 1988).

These results are not all consistent with patterns of dispersion on algae and in shallow pools described by Underwood (1976a). There, juveniles of Austrocochlea porcata (then called A. constricta) and Nerita atramentosa and all sizes of Cellana tramoserica were clearly associated with cover of water. Juvenile Bembibium nanum were not associated with water in shallow pools (i.e. were scattered at random with respect to cover of water). Here, juvenile $N$. atramentosa were more abundant in grooves and the larger pits, many of which retained water during low tide. Even though the juveniles here were much smaller than those sampled by Underwood (1976a) - <3 $\mathrm{mm}$ rather than $<10 \mathrm{~mm}$ in the previous study-results are consistent. By and large, results for B. nanum are also consistent with the previous investigation (there were no major differences for transplanted animals; in sampling, snails were equally likely to be on surfaces as in the larger features that held water).

Juvenile Austrocochlea porcata and Cellana tramoserica, however, were not mostly associated with topo- graphic features that held water, as would be expected from the results in Underwood (1976a). The simplest and most likely explanation for the differences is that the snails examined here were much smaller than those investigated previously. As a result, they can be in or even under water when there is only a thin film on an otherwise flat surface. Thus, they can be associated with water without being associated with topographic features that hold water during low tide. The only way to be sure about the potential importance or unimportance of the differences between the 2 studies would be proper tests of hypotheses using very small animals as I did here, in comparison to larger juveniles, as I did before.

It is intriguing to consider what are the consequences of selecting or avoiding some features of habitat. For all species except Bembicium nanum, small pits were ranked very low in terms of relative densities, possibly because many of these pits accumulated sediments and this reduced the available area. This did not influence similarly-sized Littorina unfasciata in similar experiments (Underwood \& Chapman 1992). In that study, small L. unifasciata were very strongly associated with cracks and small holes - even though these also accumulated sediments.

It is not at all clear which resources (food, shelter, relief from physical harshness, etc.) are provided by the various topographic features, nor how and why these differ among species. There have been several studies demonstrating that cracks and crevices can provide protection from physical harshness. For example, Fretter \& Manly (1977) described survival of tiny, newly settled Littorina neritoides only in crevices; the others were washed away by waves. Boulding \& Harper (1998) and Jones \& Boulding (1999) have described Littorina sitkana gaining relief from heatstress by moving into cracks and crevices.

Raffaelli \& Hughes (1978) pioneered the manipulation of availability of crevices to Littorina rudis and L. neritoides and demonstrated that, on an exposed shore, snails grew larger where crevices were larger. They also considered that densities of snails on a sheltered shore were regulated by availability of crevices, as also found by Emson \& Faller-Fritsch (1976). Similar outcomes were described by Chapman (1994) for highshore Nodilittorina pyramidalis, but there were also consequences of different behaviour of the snails on surfaces of different complexity (see below).

Availability of crevices can, however, apparently be a two-edged sword, in that predatory crabs can also shelter in them, increasing mortality of snails (Yamada 1977). In contrast, juvenile barnacles in crevices were less likely to be bulldozed by limpets than were those on open surfaces (Dayton 1971) and many juvenile algae survive better in areas of complex topography or 
cracks and crevices, where grazers cannot eat them (Lubchenco 1980) or where moisture enhances their growth (Jernakoff 1985). Complex topography can also influence the outcome of competition for space among barnacles (Walters \& Wethey 1986).

In detailed experimental studies of the behaviour of Littorina unifasciata and Nodilittorina pyramidalis, the snails responded to different types of surfaces in different ways. Juvenile $N$. pyramidalis were less likely to move off complex areas (Chapman 1994, Chapman \& Underwood 1994). Adults on smoother areas tended to move back to complex topographies. Similarly L. unifasciata moved much more quickly across smoother areas of rock than across topographically complex areas (Underwood \& Chapman 1989), resulting in faster turnover of populations.

Understanding the particular resources that are related to small-scale topographic features must await further experimentation. The consequences of topographic influences are also not clear for the species investigated here. The results presented here do, however, demonstrate that differentiation among species in their associations with small-scale topographic features develops early in the gastropods' intertidal lives. Very new recruits are associated with specific topographic features and respond by movement to establish these associations. This makes the intertidal life of early life-history stages of mobile animals as complex and varied as that of the adults and of more-studied sessile species. Small-scale variation in dispersion of juvenile grazers is partly explained by small-scale topographic complexity.

Acknowledgements. This study was funded by Australian Research Council Grants and through the ARC's Special Centres Programme. I am grateful to S. English, P. Scanes, W. Steel, G. Housefield, K. Astles, D. O'Connor for assistance in the field and with analyses and to Dr M. G. Chapman for insight and innovation in discussions. Some of the anonymous referees provided valuable comments.

\section{LITERATURE CITED}

Anderson RL (1959) Use of contingency tables in the analysis of consumer preference studies. Biometrics 15:582-590

Barnes H, Powell HT (1950) The development, general morphology and subsequent elimination of barnacle populations, Balanus crenatus and Balanus balanoides, after a heavy initial set. J Anim Ecol 32:107-127

Boulding EG, Harper FM (1998) Increasing precision in randomised field experiments: barnacle microtopography as a predictor of Littorina abundance. Hydrobiologia 378: 105-114

Branch GM (1981) The biology of limpets: physical factors, energy flow, and ecological interactions. Ann Rev Oceanogr Mar Biol 19:235-380

Branch GM (1984) Competition between marine organisms: ecological and evolutionary implications. Oceanogr Mar
Biol Annu Rev 22:429-593

Butman CA (1987) Larval settlement of soft-sediment invertebrates: the spatial scales of pattern explained by active habitat selection and the emerging role of hydrodynamical processes. Oceanogr Mar Biol Annu Rev 25:113-165

Caffey HM (1985) Spatial and temporal variation in settlement and recruitment of intertidal barnacles. Ecol Monogr 55:313-332

Chapman MG (1986) Assessment of some controls in experimental transplants of intertidal gastropods. J Exp Mar Biol Ecol 103:181-201

Chapman MG (1994) Small- and broad-scale patterns of distribution of the upper-shore littorinid Nodilittorina pyramidalis in New South Wales. Aust J Ecol 19:83-95

Chapman MG, Underwood AJ (1994) Dispersal of the intertidal snail, Nodilittorina pyramidalis, in response to topographic complexity of the substratum. J Exp Mar Biol Ecol 179:145-169

Connell JH (1972) Community interactions on marine rocky intertidal shores. Annu Rev Ecol Syst 3:169-192

Creese RG (1982) Distribution and abundance of the acmaeid limpet Patelloida latistrigata, and its interaction with barnacles. Oecologia 52:85-96

Crisp DJ (1974) Factors influencing the settlement of marine invertebrate larvae. In: Grant PT, Mackie AN (eds) Chemoreception in marine organisms. Academic Press, London, p $177-215$

Dakin WJ (1953) Australian sea shores. Angus \& Robertson, Sydney

Day RW, Quinn GP (1989) Comparisons of treatments after an analysis of variance. Ecol Monogr 59:433-463

Dayton PK (1971) Competition, disturbance and community organization: the provision and subsequent utilization of space in a rocky intertidal community. Ecol Monogr 41: 351-389

Denley EJ, Underwood AJ (1979) Experiments on factors influencing settlement, survival and growth of 2 species of barnacles in New South Wales. J Exp Mar Biol Ecol 36: 269-293

de Wolff PD (1973) Ecological observations on the mechanisms of dispersal of barnacle larvae during planktonic life and settling. Neth J Sea Res 6:1-129

Dunn OJ (1961) Multiple comparisons among means. J Am Stat Ass 56:52-64

Eckman JE (1996) Closing the larval loop: linking larval ecology to the population dynamics of marine benthic invertebrates. J Exp Mar Biol Ecol 200:207-237

Emson RH, Faller-Fritsch RJ (1976) An experimental investigation into the effect of crevice availability on abundance and size-structure in a population of Littorina rudis (Maton) (Gastropoda: Prosobranchia). J Exp Mar Biol Ecol 23: 285-297

Fairweather PG (1988) Predation creates haloes of bare space among prey on rocky shores in New South Wales. Aust J Ecol 13:401-409

Fretter V, Manly R (1977) Settlement and early benthic life of Littorina neritoides (L.) at Wembury, South Devon. J Moll Stud 43:255-262

Hadfield MG (1978) Metamorphosis in marine molluscan larvae: an analysis of stimulus and response. In: Chia F-S Rice ME (eds) Settlement and metamorphosis of marine invertebrate larvae. Elsevier North Holland Biomedical Press, New York, p 165-175

Jernakoff P (1985) An experimental evaluation of the influence of barnacles, crevices and seasonal patterns of grazing on the algal diversity and cover in an intertidal barnacle zone. J Exp Mar Biol Ecol 88:287-302 
Jones KMM, Boulding EG (1999) State-dependent habitat selection by an intertidal snail: the costs of selecting a physically stressful habitat. J Exp Mar Biol Ecol 242: 149-177

Lewis JR (1964) The ecology of rocky shores. English Universities Press, London

Lubchenco J (1980) Algal zonation in the New England rocky intertidal community: an experimental analysis. Ecology 61:333-344

McQuaid CD (1996) Biology of the family Littorinidae. II. Role in the ecology of intertidal and shallow marine ecosystems. Oceanogr Mar Biol Annu Rev 34:263-302

Moran MJ (1985) The timing and significance of sheltering and foraging behaviour of the predatory intertidal gastropod Morula marginalba Blainville (Muricidae). J Exp Mar Biol Ecol 93:103-114

Morse ANC, Froyd CA, Morse DE (1984) Molecules from cyanobacteria and red algae that induce larval settlement and metamorphosis in the mollusc Haliotis rufescens. Mar Biol 81:293-298

Morton J, Miller M (1973) The New Zealand seashore. Collins, London

Paine RT (1977) Controlled manipulations in the marine intertidal zone, and their contributions to ecological theory. Acad Sci Spec Publ 12:245-270

Raffaelli D, Hughes RN (1978) The effects of crevice size and availability on populations of Littorina rudis and Littorina neritoides. J Anim Ecol 47:71-84

Ricketts EF, Calvin J, Hedgpeth JW (1968) Between Pacific tides. Stanford University Press, Stanford, CA

Stimson J (1970) Territorial behavior of the owl limpet Lottia gigantea. Ecology 51:113-118

Strathmann RR, Branscomb ES, Vedder K (1981) Fatal errors in set as a cost of dispersal and the influence of intertidal flora on set of barnacles. Oecologia 48:13-18

Thompson TE (1958) The natural history, embryology, larval biology and postlarval development of Adalaria proxima (Alder and Hancock)(Gastropoda: Opisthobrancia). Phil Trans R Soc B 242:1-58

Underwood AJ (1976a) Analysis of patterns of dispersion of intertidal prosobranch gastropods in relation to macroalgae and rock-pools. Oecologia (Berl) 25:145-154

Underwood AJ (1976b) Nearest neighbour analyses of spatial

Editorial responsibility: Roger Hughes (Contributing Editor), Bangor, UK dispersion of intertidal prosobranch gastropods within 2 substrata. Oecologia 26:257-266

Underwood AJ (1979) The ecology of intertidal gastropods. Adv Mar Biol 16:111-210

Underwood AJ (1981) Structure of a rocky intertidal community in New South Wales: patterns of vertical distribution and seasonal changes. J Exp Mar Biol Ecol 51:57-85

Underwood AJ (1985) Physical factors and biological interactions: the necessity and nature of ecological experiments. In: Moore PG, Seed R (eds) The ecology of rocky coasts. Hodder \& Stoughton, London, p 371-390

Underwood AJ (1997) Experiments in ecology: their logical design and interpretation using analysis of variance. Cambridge University Press, Cambridge

Underwood AJ (2000) Experimental ecology of rocky intertidal habitats: what are we learning? J Exp Mar Biol Ecol 250:51-76

Underwood AJ, Chapman MG (1989) Experimental analyses of the influences of topography of the substratum on movements and density of an intertidal snail, Littorina unifasciata. J Exp Mar Biol Ecol 134:175-196

Underwood AJ, Chapman MG (1992) Experiments on topographic influences on density and dispersion of Littorina unifasciata in New South Wales. In: Grahame J, Mill PJ, Reid DG (eds) Proc 3rd Int Symp Littorinid Biol. Malacological Society of London, London, p 181-195

Underwood AJ, Denley EJ, Moran MJ (1983) Experimental analyses of the structure and dynamics of mid-shore rocky intertidal communities in New South Wales. Oecologia 56: 202-219

Walters LJ, Wethey DS (1986) Surface topography influences competitive hierarchies on marine hard substrata: a field experiment. Biol Bull 170:441-449

Wethey DS (1984) Spatial pattern in barnacle settlement: day to day changes during the settlement season. J Mar Biol Assoc UK 64:687-698

Wigham GD (1975) The biology and ecology of Rissoa parva (da Costa) (Gastropoda: Prosobranchia). J Mar Biol Assoc UK 55:45-68

Winer BJ, Brown DR, Michels KM (1991) Statistical principles in experimental design. 3rd edn, McGraw-Hill, New York

Yamada SB (1977) Geographic range limitation of intertidal gastropods Littorina sitkana and L. planaxis. Mar Biol 39:61-70

Submitted: May 28, 2003; Accepted: January 8, 2004

Proofs received from author(s): March 1, 2004 